\title{
Synergistic induction of cell death in liver tumor cells by TRAIL and chemotherapeutic drugs via the BH3-only proteins Bim and Bid
}

\author{
S Schneider-Jakob ${ }^{1}$, N Corazza ${ }^{1}$, A Badmann ${ }^{1}$, D Sidler ${ }^{1}$, R Stuber-Roos ${ }^{1}$, A Keogh ${ }^{2}$, S Frese ${ }^{3}$, M Tschan ${ }^{4}$ and T Brunner ${ }^{*, 1,5}$
}

Although death receptors and chemotherapeutic drugs activate distinct apoptosis signaling cascades, crosstalk between the extrinsic and intrinsic apoptosis pathway has been recognized as an important amplification mechanism. Best known in this regard is the amplification of the Fas (CD95) signal in hepatocytes via caspase 8-mediated cleavage of Bid and activation of the mitochondrial apoptosis pathway. Recent evidence, however, indicates that activation of other BH3-only proteins may also be critical for the crosstalk between death receptors and mitochondrial triggers. In this study, we show that TNF-related apoptosisinducing ligand (TRAIL) and chemotherapeutic drugs synergistically induce apoptosis in various transformed and untransformed liver-derived cell lines, as well as in primary human hepatocytes. Both, preincubation with TRAIL as well as chemotherapeutic drugs could sensitize cells for apoptosis induction by the other respective trigger. TRAlL induced a strong and long lasting activation of Jun kinase, and activation of the BH3-only protein Bim. Consequently, synergistic induction of apoptosis by TRAIL and chemotherapeutic drugs was dependent on Jun kinase activity, and expression of Bim and Bid. These findings confirm a previously defined role of TRAIL and Bim in the regulation of hepatocyte apoptosis, and demonstrate that the TRAIL-Jun kinase-Bim axis is a major and important apoptosis amplification pathway in primary hepatocytes and liver tumor cells.

Cell Death and Disease (2010) 1, e86; doi:10.1038/cddis.2010.66; published online 21 October 2010

Subject Category: Experimental Medicine

Specific and selective apoptosis induction in tumor cells is a major goal of cancer therapy. ${ }^{1,2}$ Most currently known treatments target in one or the other way the apoptosis machinery of tumor cells. However, apoptosis resistance is one of the hallmarks of cancer, and a prerequisite of transformed cells to develop into a tumor. ${ }^{3}$ Consequently, many tumor cells are highly resistant to a variety of antitumor drugs, which limits the treatment option in cancer patients. Thus, novel therapeutics, possibly targeting alternative signaling pathways and thereby bypassing apoptosis resistance, are urgently needed and the focus of intense research. Since its discovery the tumor necrosis factor family member TNF-related apoptosis-inducing ligand (TRAIL/TNFSF2) has received extensive attention because of its relatively selective induction of cell death in tumor cells. ${ }^{4}$ TRAIL promotes apoptosis in a variety of tumors of different origin, but has usually no effect on primary cells, at least under physiological conditions. For example, Walczak et al..$^{5}$ demonstrated that treatment of mice transplanted with human tumor cells resulted in growth inhibition of transplanted tumors or their eradication. In contrast, no TRAIL-induced toxicity was observed in tissue cells, for example, hepatocytes, suggesting that TRAIL may be a useful and safe future antitumor drug.
Most chemotherapeutic drugs activate the mitochondrial apoptosis pathway, and are thus selectively inhibited by high levels of antiapoptotic Bcl-2 homologs frequently seen in tumor cells. In contrast, in most cells TRAIL activates the caspase cascade directly at the receptor complex and thereby bypasses a potential mitochondria-restricted apoptosis resistance (type I cells). TRAIL may therefore induce death in cells that are resistant to other apoptosis-inducing drugs. Another interesting aspect of TRAIL is its synergy with triggers of the mitochondrial pathway, for example, chemotherapy or irradiation. Although many tumor cells show relative resistance to either TRAIL or a given chemotherapeutic drug, the combined treatment of tumor cells with both triggers often leads to a synergistic and efficient induction of cell death. This synergy between the death receptor and the mitochondrial pathway has been observed in lung cancer cells, colon carcinoma and other types of tumors. ${ }^{6-8}$

Although the synergistic induction of apoptosis by combined treatment with TRAIL and chemotherapeutic drugs is well established, their underlying mechanisms are incompletely understood. It has been suggested that DNA damage will lead to an increase in TRAIL receptor expression via the activation of the tumor suppressor and transcription factor

\footnotetext{
${ }^{1}$ Division of Experimental Pathology, Institute of Pathology, University of Bern, Bern, Switzerland; ${ }^{2}$ Clinic of Visceral and Transplantation Surgery, Inselspital, University of Bern, Bern, Switzerland; ${ }^{3}$ Clinic of Thoracic Surgery, Inselspital, University of Bern, Bern, Switzerland; ${ }^{4}$ Division of Hematology and Oncology, Department of Clinical Research, University of Bern, Bern, Switzerland and ${ }^{5}$ Division of Biochemical Pharmacology, Department of Biology, University of Konstanz, Konstanz, Germany *Corresponding author: T Brunner, Division of Biochemical Pharmacology, Department of Biology, University of Konstanz, Universitätstrasse, Konstanz 78457, Germany. Tel: + 49 (0)7531/88 5371; Fax: + 49 (0)7531/88 5372; E-mail: Thomas.brunner@uni-konstanz.de

Keywords: death receptor; mitochondria; TRAIL; liver tumors; Bcl-2 homologs; Jun kinase; hepatocytes

Abbreviations: JNK, c-Jun kinase; siRNA, small interfering RNA; TRAIL, TNF-related apoptosis-inducing ligand/TNFSF2.

Received 28.6.10; revised 09.9.10; accepted 16.9.10; Edited by G Melino
} 
p53, and thereby to increased sensitivity to TRAIL-induced apoptosis. ${ }^{9}$ Indeed, TRAIL receptor 2 is a p53-responsive target gene. ${ }^{10}$ As the synergy between TRAIL and chemotherapy is also found in p53 mutant cells, ${ }^{6}$ the p53-mediated induction of TRAIL receptor 2 is likely an incomplete explanation. Other studies have suggested that the TRAIL- and chemotherapy-induced c-Jun kinase (JNK) pathway may have an important role in the synergistic induction of cell death. ${ }^{11}$

Although primary cells are mostly resistant to TRAILinduced apoptosis, there is increasing evidence that TRAIL can modulate and enhance apoptosis induced by other triggers even in primary cells. Of particular interest in this regard is the role of TRAIL in hepatocyte apoptosis. Although in vivo administration of the TNF homolog Fas ligand causes rapid death because of the induction of excessive liver damage, therapeutic doses of TRAIL seem to be tolerated well. ${ }^{5}$ We recently described that TRAIL fails to trigger apoptosis in primary hepatocytes but enhances their sensitivity to the Fas pathway. ${ }^{12}$ Synergistic induction of hepatocyte apoptosis in vitro and liver damage in vivo was found to be dependent on TRAIL-induced activation of JNK and the pro-apoptotic Bcl-2 homolog Bim. Interestingly, a similar pathway has been described for TNF $\alpha$-mediated liver damage ${ }^{13}$ suggesting that the JNK-Bim axis is an important response modifier pathway.

In this study, we investigated the role of the JNK-Bim axis in the synergistic induction of apoptosis by TRAIL and chemotherapeutic drugs in human liver tumor cells and hepatocytes. Our data confirm the potentiation of the mitochondrial pathway by TRAIL in hepatoma cell lines, hepatocellular carcinoma cell lines, immortalized hepatocytes as well as primary human hepatocytes. TRAIL but not chemotherapy induced a strong activation of JNK and subsequent phosphorylation of Bim. Synergistic induction of apoptosis by TRAIL and doxorubicin was associated with increased binding of Bim to $\mathrm{Mcl}-1$, activation of Bax, release of Cytochrome $c$ and SMAC from the mitochondria, and increased activation of caspases. Inhibition of JNK, knockdown of Bim and Bid by RNA interference, or overexpression of $\mathrm{Mcl}-1$ and $\mathrm{Bcl}-\mathrm{x}_{\mathrm{L}}$ efficiently inhibited cell death induced by the combined treatment of cells with TRAIL and chemotherapy. These findings demonstrate that TRAIL-JNK-Bim axis is a major and important apoptosis amplification pathway in primary hepatocytes and liver tumor cells.

\section{Results}

Synergistic induction of apoptosis by TRAIL and doxorubicin in liver tumor cells. Synergistic induction of cell death by TRAIL and chemotherapeutics has been described in different tumors cell lines. ${ }^{6-8,14}$ Similarly, we have previously reported that TRAIL can enhance the Fas-induced apoptosis pathway in hepatocytes via a JNK-Bim-dependent pathway. ${ }^{12}$ To investigate whether the TRAIL-initiated JNK-Bim pathway has also major role in the induction of cell death by TRAIL and chemotherapy, we assessed cell death induced by TRAIL and doxorubicin in different liver tumor cell lines as well as immortalized human hepatocytes (IHHs). Figure 1a illustrates that doxorubicin was found to be an inefficient inducer of cell death in HepG2 and Huh7 cells, and only a weak inducer of apoptosis in Hep3B and IHH cells. Similarly, only weak induction of cell death was seen in these cell lines with TRAIL concentrations up to $50 \mathrm{ng} / \mathrm{ml}$. In marked contrast, when cell lines were preincubated with $10 \mathrm{ng} / \mathrm{ml}$ TRAIL for $30 \mathrm{~min}$ before the treatment with increasing concentrations of doxorubicin a profound sensitization and strongly increased cell death induction was seen in all cell lines. Interestingly, an identical sensitization was seen when cells were preincubated for $30 \mathrm{~min}$ with $1 \mu \mathrm{g} / \mathrm{ml}$ doxorubicin and then stimulated with TRAIL. This synergistic induction of cell death was confirmed by detection of caspase activity (DEVD cleavage; Figure 1b) and annexin $\mathrm{V}$ staining (Figure $1 \mathrm{c}$ ). These data confirm that TRAIL and doxorubicin synergistically induce apoptosis in different liver-derived cell lines.

Synergistic induction of cell death is not dependent on preconditioning. We next investigated whether preincubation with either doxorubicin or TRAIL was required for the synergistic enhancement of cell death induction by the respective other agonist. HepG2 cells were thus pretreated with low doses of TRAIL or doxorubicin for $60 \mathrm{~min}$, before stimulation with increasing concentrations of doxorubin or TRAIL. Alternatively, both triggers were added simultaneously. Interestingly, the synergistic induction of cell death by TRAIL and doxorubicin was as efficient when pretreated for 60 min with one agonist and then treated with the other, or when triggers were added at the same time. Similarly, no difference was seen whether cells were preconditioned by TRAIL or doxorubicin (Figure 2).

TRAIL synergizes with different mitochondrial triggers. To further explore whether this synergistic induction of cell death was restricted to the combination TRAIL-doxorubicin, or further extends to other apoptosis triggers, HepG2 cells were preconditioned with medium control or low concentrations of TRAIL, and then exposed to staurosporin, irinotecan (CPT-11), 5 fluorouracil or cisplatin. Remarkably, although most of these agonists alone were relatively inefficient triggers of apoptosis in HepG2 cells, pretreatment with TRAIL greatly sensitized cells to apoptosis induction by these mitochondrial triggers (Figure 3). Similar findings were made for Hep3B cells (data not shown).

Role of JNK in synergistic induction of cell death. We previously described that in murine hepatocytes, TRAIL synergistically enhanced the Fas apoptosis pathway via a JNK-Bim-dependent process. ${ }^{12}$ The role of JNK activation was thus analyzed in TRAIL-mediated enhancement of chemotherapy-induced cell death in liver tumor cells. HepG2 cells were treated with doxorubine, TRAIL or the combination thereof for various time points, and the activation of JNK was monitored by the detection of phospho-JNK (Figure 4a). Notably, whereas both doxorubicin and TRAIL induced JNK activation within $30 \mathrm{~min}$, TRAIL seemed to be a more potent inducer of JNK activation. Combined treatment of cells with TRAIL and 
doxorubicin did not result in a substantial increase in JNK activation

HepG2 cells were then pretreated with increasing concentrations of JNK inhibitor II, and apoptosis sensitivity to the combination of TRAIL and doxorubicin was analyzed.
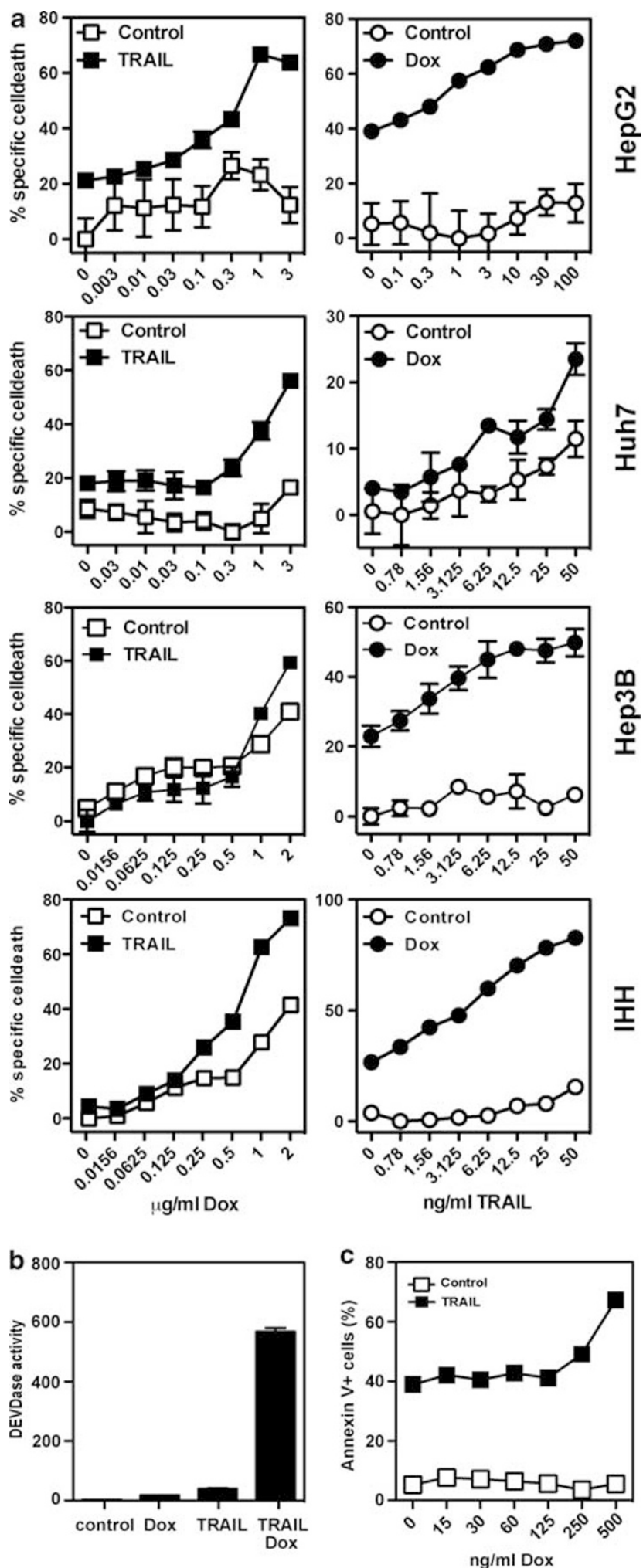

Pretreat: $\quad$ TRAIL
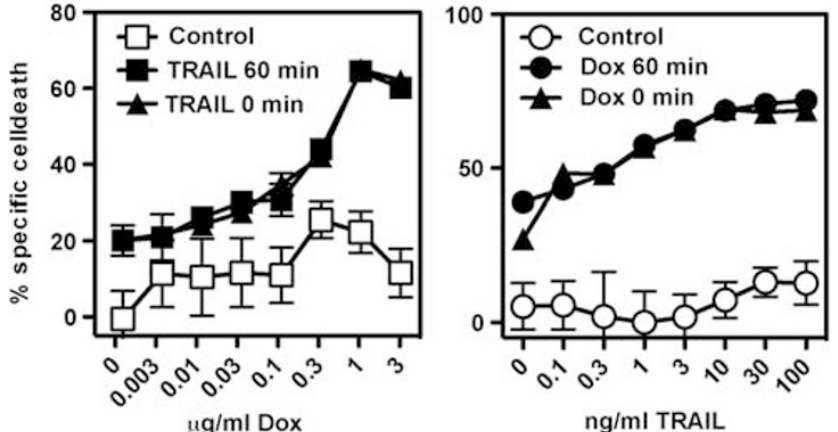

$\mathrm{ng} / \mathrm{ml}$ TRAIL

Figure 2 Effects of pretreatment on synergistic induction of cell death. HepG2 cells were pretreated with medium control, TRAlL (left panel, $10 \mathrm{ng} / \mathrm{ml}$ ) or doxorubicin (Dox, right panel, $1 \mu \mathrm{g} / \mathrm{ml}$ ), either $60 \mathrm{~min}$ before adding increasing doses of doxorubicin or TRAIL, or directly together with the apoptosis trigger ( $0 \mathrm{~min}$ ). Cell death was measured by MTT assay. Mean values \pm S.D. of quadruplicates are shown. $n=2$
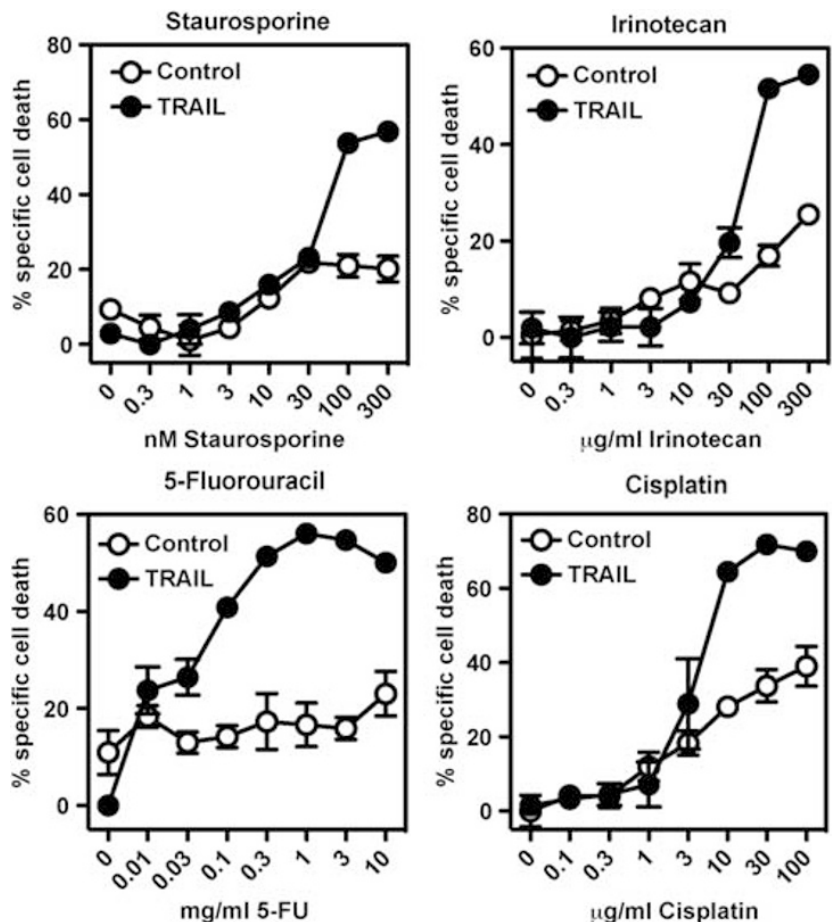

Figure 3 TRAIL synergizes with different chemotherapeutic drugs. HepG2 cells were either pretreated with medium control or $10 \mathrm{ng} / \mathrm{ml}$ TRAIL, and then exposed to increasing concentrations of staurosporin, irinotecan, 5-fluorouracil (5-FU) or cisplatin. Cell death was measured by MTT assay. Mean values \pm S.D. of quadruplicates are shown. $n=2$

Figure 1 Synergistic induction of cell death by doxorubicin and TRAIL. (a) HepG2, Huh7, Hep3B and IHH cells were pretreated by either medium control, $10 \mathrm{ng} / \mathrm{ml}$ TRAIL (left panels) or $1 \mu \mathrm{g} / \mathrm{ml}$ doxorubicin (Dox, right panels), before the exposure to increasing concentration of doxorubicin (left panels) or TRAIL (right panels). Cell death was measured by MTT assay. Mean values \pm S.D. of quadruplicates of a typical experiment $(n=3)$ are shown. (b) HepG2 cells were treated with $1 \mu \mathrm{g} / \mathrm{ml}$ doxorubicin, $10 \mathrm{ng} / \mathrm{ml}$ TRAIL or the combination thereof for $6 \mathrm{~h}$, and DEVDase activity in cell lysates was measured. Mean values \pm S.D. of quadruplicates were measured. $n=3$. (c) HepG2 cells were pretreated with medium control or $10 \mathrm{ng} / \mathrm{ml}$ TRAIL, and then exposed to increasing doses of doxorubicin. Apoptosis was measured by Annexin V binding. $n=2$ 

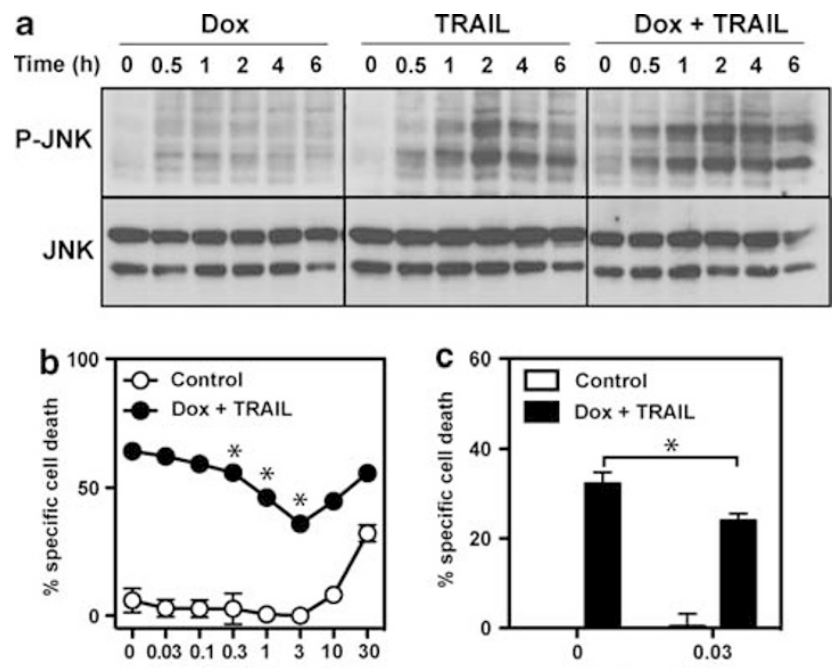

$\mu \mathrm{M}$ JNK Inhib. II

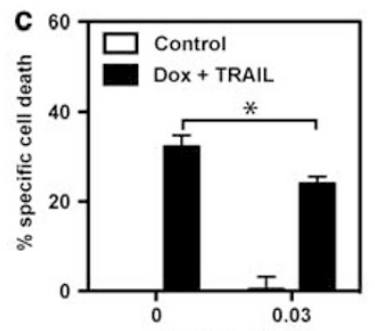

$\mu \mathrm{M}$ JNK Inhib. V

Figure 4 Role of JNK in TRAIL plus doxorubicin-induced cell death. (a) HepG2 cells were treated for indicated time with doxorubicin (Dox, $1 \mu \mathrm{g} / \mathrm{ml})$, TRAlL $(10 \mathrm{ng} / \mathrm{ml})$ or the combination of both. Phosphorylated JNK (P-JNK) and total JNK as loading control were detected by western blot. (b) Cells were pretreated for $30 \mathrm{~min}$ with increasing concentrations of JNK inhibitor (inhib.) II and then exposed to medium control or $1 \mu \mathrm{g} / \mathrm{ml}$ doxorubicin plus $30 \mathrm{ng} / \mathrm{ml}$ TRAlL. (c) Cells were pretreated with 0.03 uM JNK inhibitor V, and then exposed to medium control or doxorubicin plus TRAIL. Cell death was measured by MTT assay, mean values \pm S.D. of quadruplicates are shown. $n=3$. ${ }^{*} P<0.01$ (control treated versus JNK inhibitor treated)

Although the JNK inhibitor II was found to be toxic at concentrations $10 \mu \mathrm{M}$ or higher, it dose dependently inhibited the synergistic induction of cell death by TRAIL and doxorubicin at lower doses (Figure 4b). A similar inhibition of cell death induction by TRAIL plus doxorubicin was seen when cells were treated with the JNK V inhibitor (Figure 4c). These data suggested that JNK is involved in the sensitization of cells for apoptosis induction.

TRAIL promotes Bim phosphorylation. $\mathrm{We}^{12}$ and others $^{13}$ have previously identified Bim as an important target of JNK in murine hepatocytes. The phosphorylation of Bim in response to doxorubicin, TRAIL, or the combination of both was thus analyzed in HepG2 cells. Interestingly, Bim $\mathrm{EL}$ was hardly detectable in NP-40 lysates of untreated control cells, but became rapidly mobilized after treatment with doxorubicin or TRAIL (Figure 5a). Likely, this represents a release of $\mathrm{Bim}_{\mathrm{EL}}$ from intracellular (NP40-resistant) stores,

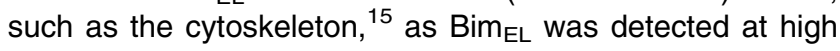
levels in SDS lysates of control cells (Figure 5b). Although in doxorubicin-treated cells Bim $_{\mathrm{EL}}$ remained predominantly in its unphosphorylated form, treatment of cells with TRAIL resulted in a time-dependent increase of higher molecular weight variants, indicative of $\mathrm{Bim}_{\mathrm{EL}}$ phosphorylation. ${ }^{12,13,16}$ Although Bim $\mathrm{EL}_{\mathrm{L}}$ levels remained stable in doxorubicin- or TRAIL-stimulated cells, combined treatment with doxorubicin and TRAIL resulted in the disappearance of Bim $\mathrm{EL}_{\mathrm{L}}$, indicating consumption of Bim in dying cells (Figure $5 \mathrm{~b}$ ).

JNK induces activation of Bim. Previous studies have indicated that the JNK-mediated phosphorylation represents

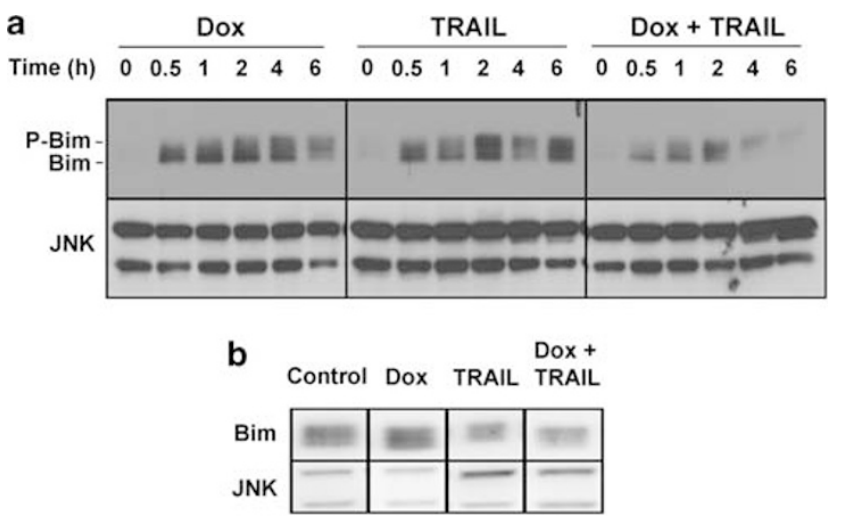

Figure 5 TRAIL promotes Bim mobilization and phosphorylation. (a) HepG 2 cells were treated for indicated time with $1 \mu \mathrm{g} / \mathrm{ml}$ doxorubicin (Dox), $10 \mathrm{ng} / \mathrm{ml} \mathrm{TRAlL}$, or the combination thereof. Bim levels in NP40 lysates were analyzed by western blot. Detection of JNK was used for loading control. Positions of Bim and phosphorylated Bim (P-Bim) are shown. (b) Cells were treated as indicated above for $4 \mathrm{~h}$, lyzed in SDS buffer and total Bim and JNK levels were analyzed by western blot

an activation step for $\mathrm{Bim}_{\mathrm{EL}}$ and downstream apoptosis pathway. ${ }^{12,13,16-18}$ As Bim $_{\mathrm{EL}}$ strongly binds and neutralizes the antiapoptotic Bcl-2 homolog $\mathrm{Mcl}-1,{ }^{19}$ we analyzed the apoptosis trigger-induced binding of $\mathrm{Bim}_{\mathrm{EL}}$ to $\mathrm{Mcl}-1$ in the presence of a JNK inhibitor. When Mcl-1 was immunoprecipitated and bound $\mathrm{Bim}_{\mathrm{EL}}$ was detected by

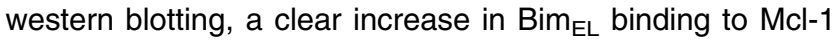
was noted in response to TRAIL and doxorubicin treatment. In contrast, no increase in Bim binding to $\mathrm{Mcl}-1$ was found in JNK inhibitor-pretreated cells (Figure 6a). Total Bim $\mathrm{EL}_{\mathrm{L}}$ and Mcl-1 levels were similar under these conditions, apart from reduced levels of $\mathrm{Mcl}-1$ in TRAIL and doxorubicin-treated cells in the absence of JNK inhibitor, likely representing $\mathrm{Mcl}-1$ degradation in dying cells. ${ }^{20}$

TRAIL and chemotherapy synergistically activate the mitochondrial pathway. The synergistic activation of Bim by TRAIL and doxorubicin suggested a strong activation of the mitochondrial apoptosis pathway. Activation of Bax, a pro-apoptotic $\mathrm{Bcl}-2$ homolog critically involved in the permeabilization of the outer mitochondrial membrane and the release of Cytochrome $c$, was therefore analyzed by immunoprecipitation of active Bax using an anti-N-terminus antibody under native conditions. Although no active Bax could be pulled down in control or doxorubicin-treated cells, and only low levels in TRAIL-treated cells, combined treatment with TRAIL and doxorubicin resulted in a strong increase of Bax activation (Figure 6b). This increased Bax activation was paralleled with an increased mitochondrial outer membrane permeabilization and release of Cytochrome $c$ and SMAC (Figure 6c). In agreement with an induction of the mitochondrial apoptosis pathway, doxorubicin plus TRAIL-induced caspase activation was efficiently blocked by the overexpression of $\mathrm{Mcl}-1$ and $\mathrm{Bcl}-\mathrm{x}_{\mathrm{L}}$ (Figure $6 \mathrm{~d}$ ).

Critical role for Bim and Bid in the synergistic induction of cell death by TRAIL and doxorubicin. Hepatocytes and hepatocyte-derived cells are known to require the caspase 
a

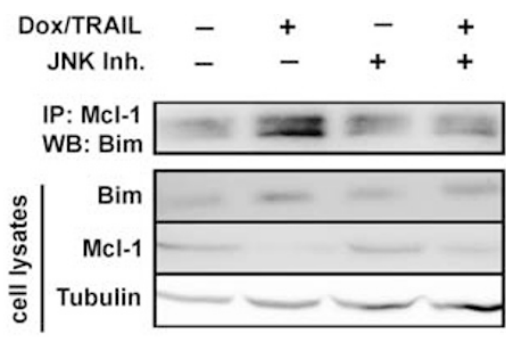

c

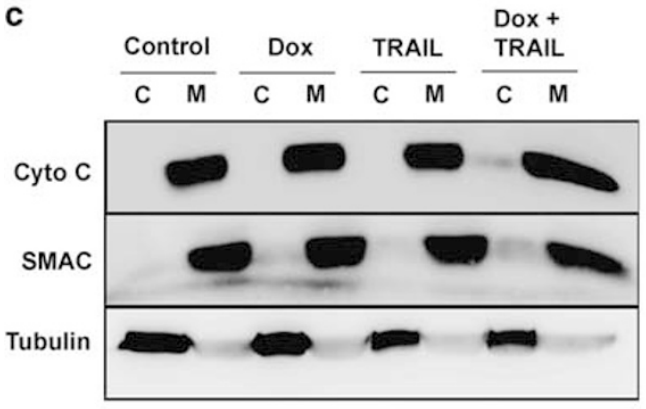

b

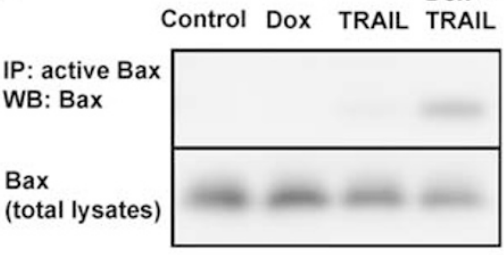

d

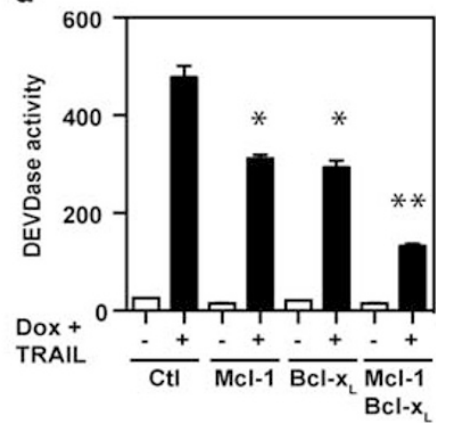

Figure 6 TRAIL plus chemotherapy activates the mitochondrial apoptosis pathway. (a) HepG2 cells were pretreated with or without JNK inhibitor (Inh) and the stimulated with medium control (Ctl) or doxorubicin (Dox; $1 \mu \mathrm{g} / \mathrm{ml}$ ) plus TRAIL (10 ng/ml). Cells were lysed, Mcl- 1 was immunoprecipitated and Bim bound to Mcl-1 was detected by western blot. Bim, Mcl-1 and tubulin levels in total cell lysates were analyzed for comparison. (b) Cells were treated with doxorubicin, TRAIL or both, and active Bax was immunoprecipitated and detected by western blot. Bax in total lysates was analyzed for comparison. (c) Cells were treated with doxorubicin, TRAIL or both, and cytoplasmic (C) and mitochondrial fractions (M) were isolated. Cytochrome $c$ (Cyto $c$ ), SMAC and for comparison tubulin in the different fractions were analyzed by western blot. (d) Cells were transfected with control plasmid, Mcl-1, Bcl-xL or both, and then exposed to medium control or doxorubicin plus TRAIL. After $6 \mathrm{~h}$ DEVDase activity in cell lysates was analyzed. Mean values \pm S.D. of quadruplicates are shown. $n=3$. ${ }^{\star} P<0.005,{ }^{\star \star} P<0.001$, compared with control transfection

8-mediated cleavage of the BH3-only protein Bid in order to amplify death receptor signals via the mitochondrial pathway (type II cells). ${ }^{21,22}$ We thus investigated whether the synergistic induction of cell death by TRAIL and doxorubicin would also affect the caspase-mediated cleavage and activation of Bid. Although no Bid processing was detectable upon stimulation with TRAIL or doxorubicin alone, the combination thereof caused a time-dependent appearance of truncated Bid, suggesting activation of Bid (Figure 7a).

To assess the relative contribution of the $\mathrm{BH} 3$-only proteins Bid and Bim in TRAIL plus doxorubicin-induced cell death, expression of these pro-apoptotic $\mathrm{Bcl}-2$ homologs was reduced by RNA interference (Figure 7b), and caspase activation in response to TRAIL, doxorubicin or both was assessed (Figure 7c). Although downregulation of Bim or Bid alone already resulted in reduced TRAIL plus doxorubicininduced DEVDase activity, combined knockdown of Bid and Bim was most efficient in preventing caspase activation, indicating that both $\mathrm{BH}$-only proteins are involved in mediating synergistic induction of cell death by TRAIL and doxorubicin.

TRAIL and doxorubicin sensitize primary hepatocytes. TRAIL has gained considerable interest for the use in cancer therapy because of its selective apoptosisinducing activity in tumor but not primary tissue cells. ${ }^{4,5}$ However, we have recently demonstrated that TRAIL can sensitize primary hepatocytes to Fas-induced apoptosis in a JNK-Bim-dependent manner. ${ }^{12}$ As JNK and Bim seem to be involved also in TRAIL-induced sensitization to chemotherapeutics in hepatocellular carcinomas, we wondered whether TRAIL could also sensitize primary human hepatocytes to doxorubicin-induced apoptosis. As reported previously, ${ }^{4,5}$ TRAIL alone did not induce cell death in primary hepatocytes even at very high concentrations (up to $1000 \mathrm{ng} / \mathrm{ml}$ ). Similarly, even $3 \mu \mathrm{g} / \mathrm{ml}$ doxorubicin failed to promote apoptosis. In marked contrast, even low concentrations of TRAIL strongly sensitized human hepatocytes to doxorubicin-induced cell death, and vice versa (Figure 8). These findings indicate that the synergistic induction of cell death by TRAIL and chemotherapeutics is not restricted to immortalized and tumor cells of the liver, but also extends to primary hepatocytes.

\section{Discussion}

Induction of apoptosis is a major goal of various antitumor therapies, ${ }^{23}$ however, a hallmark of cancer is also the increased resistance of tumor cells toward apoptosis induction. ${ }^{3}$ Consequently, the combined treatment of tumor cells with an apoptosis sensitizer and an apoptosis inducer would appear a perfect strategy to efficiently promote tumor cell death and thus tumor regression. Particularly in this regard TRAIL has received enormous attention. Although many tumor cells are resistant to TRAIL or chemotherapy, various publications in different types of tumors revealed that the combined treatment of tumor cells with TRAIL and chemotherapeutic drugs substantially sensitizes them for apoptosis induction. ${ }^{6-8,14}$ As different underlying mechanisms for this 
a

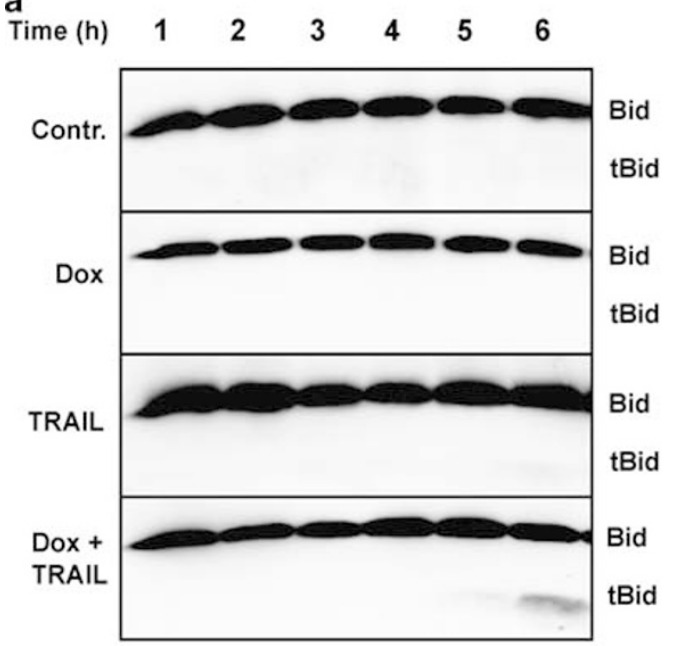

b
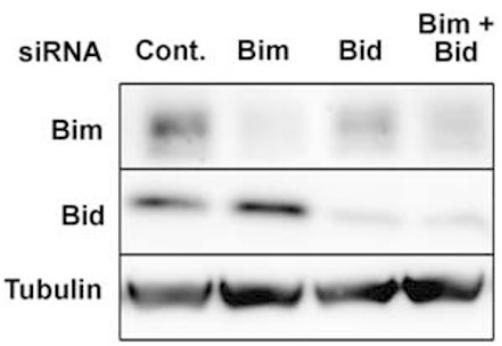

C

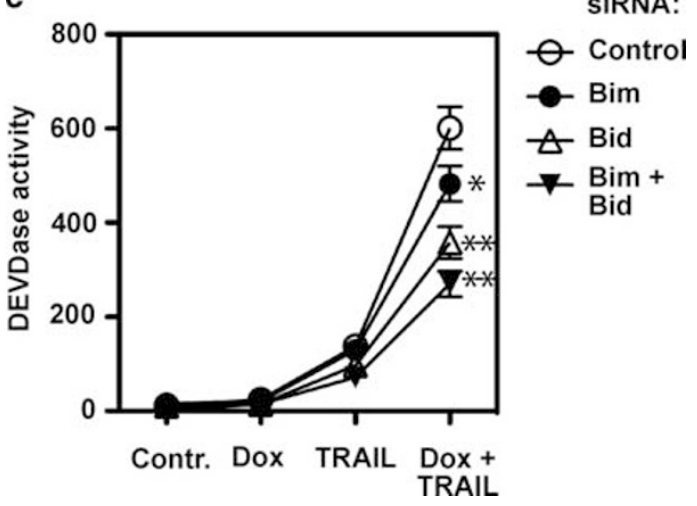

Figure 7 Role of Bid and Bim in TRAIL plus doxorubicin (Dox)-induced cell death. (a) HepG2 cells were treated with doxorubicin, TRAIL or both for indicated time intervals and Bid cleavage was analyzed by western blot. (b) HepG2 cells were transfected with control (Contr.) siRNA, Bim or Bid specific siRNA or the combination of both. Downregulation of Bim and Bid was analyzed by western blot. Tubulin was used as loading control. (c) Cells were treated with siRNA as indicated above and apoptosis sensitivity to doxorubicin $(1 \mu \mathrm{g} / \mathrm{ml})$, TRAIL $(10 \mathrm{ng} / \mathrm{ml})$ or both was analyzed by DEVDase clevage assay. Mean values \pm S.D. of quadruplicates are shown. $n=3 .{ }^{*} P<0.005,{ }^{*} P<0.0005$ compared with control siRNA. tBid, truncated Bid

sensitization have been proposed, it is often not clear which one is the sensitizer and which one is the apoptosis inducer. Likely this distinction is even difficult to be made, or not relevant, as the sensitization to efficient apoptosis induction depends on both, the sensitizer and the apoptosis inducer.

In this study, we have shown that different hepatocellular tumor cells, as well as immortalized and primary hepatocytes,

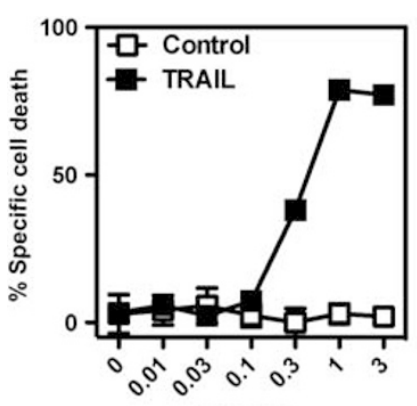

$\mu \mathrm{g} / \mathrm{ml} \mathrm{Dox}$

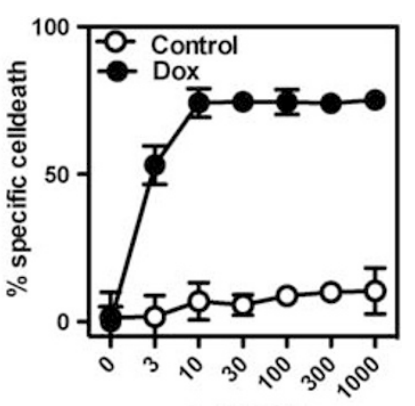

$\mathrm{ng} / \mathrm{ml}$ TRAIL
Figure 8 TRAIL plus doxorubicin (Dox) induces cell death in primary human hepatocytes. Primary human hepatocytes were pretreated with $10 \mathrm{ng} / \mathrm{ml}$ TRAIL and then exposed to increasing doses of doxorubicin (left panel), or pretreated with $1 \mu \mathrm{g} / \mathrm{ml}$ doxorubicin and then stimulated with increasing doses of TRAIL. Cell death was analyzed after $16 \mathrm{~h}$ by MTT assay. Mean values of quadruplicates \pm S.D. are shown. $n=2$

are greatly sensitized to apoptosis induction by combined treatment with TRAIL and chemotherapeutic drugs. In line with the above discussed distinction, we have observed that pretreatment with either TRAIL or doxorubicin sensitized tumor cells for apoptosis induction by the respective other trigger. Cell death induction was even comparable when both triggers were added simultaneously, indicating that the sensitizing event occurs rapidly enough to enhance the apoptosis-inducing step. Although this sensitization worked reproducibly in a number of different hepatocellular tumor cell lines, we also found that primary human hepatocytes were equally sensitized to apoptosis induction by the combined treatment with TRAIL and doxorubicin. This was particularly remarkable as none of the triggers alone promoted cell death alone, in line with the reported insensitivity of hepatocytes to TRAIL and chemotherapy. 5,24 This finding points out a potential adverse liver-damaging side effect of combinational tumor therapy with chemotherapeutic drugs and TRAIL. In support of this observation is a recent report demonstrating that the antineoplastic agent 5-azacytidine sensitizes primary human and murine hepatocytes for death receptor-induced apoptosis. ${ }^{25}$ Similarly, we have previously demonstrated that Fas-induced hepatocyte apoptosis and liver damage is strongly enhanced by TRAIL. ${ }^{12}$ Furthermore, Koschny et al. ${ }^{26}$ described that primary human and murine hepatocytes are sensitized to TRAIL-induced apoptosis by the proteosome inhibitor bortezomib, though higher concentrations of bortezomib were needed than in hepatocellular carcinoma cells. Regarding the combination doxorubicin and TRAIL we observed a comparable sensitization pattern in hepatocellular tumor cells and primary hepatocytes (Figures 1 and 8 ). Clearly, all of the findings support the idea that TRAIL plus an additional trigger is required to promote efficient apoptosis in primary hepatocytes. This stands in contrast with the finding of Jo et al., ${ }^{27}$ who described that TRAIL alone was sufficient to promote apoptosis in primary human hepatocytes. Differential preconditioning of hepatocyte preparations in the respective donor or by isolation techniques, and associated stress signals, could at least in part explain the observed sensitivity to TRAIL alone. 
Although it is well established that chemotherapeutic drugs and death ligands strongly synergize in various cell types, the respective mechanisms of sensitization or synergy are not always clear, or may differ from cell type to cell type. Possible mechanisms of chemotherapy-induced enhancement of death receptor-induced apoptosis include p53-induced death receptor expression (e.g., Fas and TRAIL-R2) ${ }^{28,29}$ or enhanced death receptor signaling complex assembly and thus increased downstream caspase activation. ${ }^{30,31}$ More recent evidence suggests that TRAIL and chemotherapeutic drugs target a common signaling pathway, which involves a JNK-mediated activation or induction of Bim. The BH3-only molecule Bim has an essential role in various forms of apoptosis in different cell types. For example, Bim has been implicated in glucocorticoid receptor-, chemotherapy-, irradiation- and growth factor withdrawal-induced apoptosis in tumor cells and primary cells, such as thymocytes. ${ }^{32}$ Treatment of cells by apoptosis triggers often leads to an induction of Bim expression, either in an AP-1 or Foxo3a-dependent manner. ${ }^{33-35}$ This induction of Bim is particularly evident in glucocorticoid- and $T$ cell receptor-induced apoptosis in thymocytes, ${ }^{36,37}$ and Bim-deficient thymocytes show increased resistance to $T$ cell receptor and glucocorticoidinduced apoptosis. However, as many cells constitutively express relatively high levels of Bim in the apparent absence of apoptosis, it is very likely that post-translational modifications significantly contribute to the regulation of Bim-mediated cell death. Thus, it was shown that in unstressed cells Bim is sequestered by the dynein motor complex and released upon exposure of cells to apoptosis triggers. ${ }^{15,18}$ In line with this finding, we observed that Bim was hardly detectable in cells lysed with NP40, but became rapidly mobilized (within $30 \mathrm{~min}$ ) after treatment with TRAIL or doxorubicin (Figure 5). As total Bim levels remained unchanged (in SDS lysates), it is feasible to believe that apoptosis triggers promote a mobilization and redistribution of Bim within the cell, likely promoting translocation of Bim to the mitochondrial membrane, in which it engages other $\mathrm{Bcl} 2$ homologs and promotes apoptosis. ${ }^{15,18}$

Another important level of regulation is the phosphorylation of Bim by either ERK or JNK. Whereas phosphorylation of Bim $_{\mathrm{EL}}$ by ERK promotes its degradation via the proteosome and thereby enhances cell survival, phosphorylation of Bim $\mathrm{EL}$ by JNK seems to enhance its apoptotic activity. ${ }^{16,17,38}$ Analysis of apoptosis sensitivity of cells from mutant mice with targeted mutation of the ERK or JNK phosphorylation site

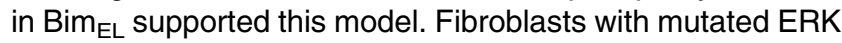
phosphorylation sites showed increased Bim $\mathrm{EL}_{\mathrm{L}}$ stability and increased growth factor withdrawal-induced apoptosis, whereas thymocyte with a mutated JNK phosphorylation site in Bim $_{E L}$ were found to be less sensitive to anti-CD3 and dexamethasone. $^{38}$ In line with this notion, we recently observed that Fas-induced hepatocyte apoptosis and liver destruction is substantially regulated via a TRAIL-initiated JNK-mediated activation of Bim. ${ }^{12}$ Absence or inhibition of either TRAIL, JNK or Bim resulted in significantly reduced hepatocyte apoptosis. Along these lines, Kaufmann et al. ${ }^{13}$ found that TNF $\alpha$-mediated liver destruction was similarly enhanced via the JNK-Bim axis.

In this study, we provide further evidence for the importance of the death receptor-JNK-Bim axis in regulating mitochondrial apoptosis in transformed and primary liver cells. Although we found that both doxorubicin and TRAIL alone were able to promote Bim mobilization from intracellular stores, only combined treatment of cells with TRAIL and chemotherapeutic drugs efficiently triggered cell death. TRAIL treatment of cells resulted in JNK activation and phosphorylation of $\mathrm{Bim}_{\mathrm{EL}}$, and in agreement with their respective role in promoting cells death, apoptosis was blocked by JNK inhibitors or knocking down Bim. As TRAIL alone failed to promote apoptosis, this Bim activation step is likely not sufficient, and efficient induction of cell death may require the simultaneous activation of different $\mathrm{BH} 3$-only molecules. In agreement with this idea we have seen that Bid was also involved in TRAIL plus doxrubicine induced apoptosis, and combined knockdown of $\mathrm{Bim}$ and Bid further reduced apoptosis induction. Other studies in cells from double BH3only mutant mice support the idea that combined activation of different BH3-only molecules and simultaneous engagement of different downstream effectors may be required for efficient cell death induction. ${ }^{32,39,40}$

In summary, our studies demonstrate a critical role of JNKmediated Bim activation in the TRAIL-mediated enhancement of chemotherapy-induced apoptosis in liver-derived cells lines, further supporting the importance of the TRAIL-JNKBim axis in regulating apoptosis. As the synergistic induction of cell death by TRAIL and doxorubicin was also observed in untransformed primary human hepatocytes, our results also point out potentially deleterious effects of TRAIL combination therapy in promoting undesired liver destruction. Defined manipulation or regulation of these processes may thus help to either enhance tumor therapy or prevent tumor therapyinduced tissue toxicity.

\section{Materials and Methods}

Cells and cell lines. The human hepatoma cell line HepG2 (ATCC HB-8065), the human hepatocellular carcinoma cell lines Huh $7^{41}$ and Hep3B (ATCC HB-8064), and the $\mathrm{IHH}$ cell line $\mathrm{HH}^{42}$ were kindly provided by J-F Dufour (Institute of Clinical Pharmacology, Inselspital, University of Bern, Switzerland). Cell were cultured in IMDM containing $5 \% \mathrm{FCS}, 1 \% \mathrm{~L}$-glutamine and $0.1 \%$ gentamycin. The isolation and culture of primary human hepatocytes from human liver specimens has been described previously. ${ }^{43}$ Human hepatocytes were cultured in Williams $E$ medium containing 10\% FCS, 1\% L-glutamine, $0.1 \%$ gentamicin, $0.01 \%$ insulin/aprotinin and $0.05 \%$ transferrin. All media components were from Sigma-Aldrich (Buchs, Switzerland).

Cell death assays. HepG2, Hep3B, Huh7 and IHH were grown in logarithmic phase, harvested and plated in 96-well flat bottom plates. Primary human hepatocytes were directly seeded into collagen-coated 96-well flat bottom plates. After overnight adherence, medium was changed and cells were treated with increasing concentrations of recombinant human TRAIL (untagged form, R\&D Systems, Abington, UK) and doxorubicin (Alexis, Lausen, Switzerland), staurosporin (Sigma-Aldrich), irinotecan (camptothecin, Alexis), 5-fluorouracil (Valeant, Aliso Viejo, CA, USA), or cisplatin (Alexis) for $16 \mathrm{~h}$. Cell viability was the assessed by MTT assay (Sigma-Aldrich) and normalized to untreated controls, as described previously. ${ }^{12}$ Alternatively, cell death was also monitored by Annexin $V$ staining. ${ }^{44}$ In some experiments cells were pretreated with Jun kinase inhibitor II or V (Calbiochem, Merck, Darmstadt, Germany) for $30 \mathrm{~min}$, before the induction of cell death.

Caspase activity assay (DEVDase activity). Cells were treated with TRAIL and/or drugs as indicated, and harvested after $6 \mathrm{~h}$. Cells were then washed and lysed for $10 \mathrm{~min}$ on ice with $200 \mathrm{ul}$ PBS containing $1 \%$ Triton X-100. After centrifugation for $5 \mathrm{~min}$ at $16000 \times g$ at $4{ }^{\circ} \mathrm{C}$, supernatant was harvested and $50 \mu \mathrm{l}$ were mixed with $150 \mu \mathrm{l}$ Hepes buffer (100 mM Hepes pH 7.5, 20\% glycerol, $0.5 \mathrm{mM}$ 
EDTA, $5 \mathrm{mM}$ DTT) containing $100 \mu \mathrm{M}$ Ac-DEVD-AFC (Alexis). Reactions were incubated for $1 \mathrm{~h}$ at $37^{\circ} \mathrm{C}$, and enzymatic activity was measured on a spectrofluorometer $(400 \mathrm{~nm}$ excitation, $505 \mathrm{~nm}$ emission). Background fluorescence was measured by incubating caspase substrate with lysis buffer.

Western blotting and immunoprecipitation. After cell death induction for different time intervals and using different trigger combinations, cells were harvested, washed and lysed in cell lysis buffer (1\% NP40, $50 \mathrm{mM}$ Tris pH 8.0, $150 \mathrm{mM} \mathrm{NaCl}, 0.5 \%$ deoxycholic acid. In some instances, cells were directly lysed in SDS-PAGE loading buffer containing 1\% SDS (total lysates). After removal of insoluble matter and nuclei, equal amounts of protein were separated on a SDS-PAGE and transferred to a nitrocellulose membrane. Specific proteins were then detected using antibodies for JNK, phospho-JNK (both from Cell Signaling Technology, Bioconcept, Allschwil, Switzerland), Bim (Sigma-Aldrich), Bid (BD Biosciences, Basel, Switzerland), Mcl-1 (BD Biosciences) and Bax (Upstate, Milipore, Zug, Switzerland). Equal loading was confirmed by detection of JNK or tubulin.

In some experiments, Mcl-1 was immunoprecipitated using anti-Mcl-1 antibody and Bim bound to Mcl-1 was detected by western blotting. Bax activation was detected by immunoprecipitation of active Bax using an anti-Bax NT antibody (Upstate) and detection by western blotting.

Cytochrome $c$ and SMAC release assay. Cytochrome $c$ and SMAC release from mitochondria into the cytoplasm was analyzed by western blot as described previously. ${ }^{45}$

Downregulation of Bim and Bid by small interfering RNA (siRNA). Cells were transfected with $10 \mathrm{nM}$ control, Bim- or Bid-specific siRNA (Dharmacon, Lafayette, CO, USA) and $20 \mathrm{ul}$ Hyperfect reagents (Qiagen, Hombrechtikon, Switzerland) in $6 \mathrm{~cm}$ culture dishes over night. After washing cells were harvested and redistributed into 96-well plates. After an additional $24 \mathrm{~h}$ culture, cells were exposed for $6 \mathrm{~h}$ to apoptosis-inducing triggers. Cells were then harvested, lyzed and analyzed for DEVDase activity, and Bim and Bid expression by western blot.

Transfection and overexpression. HepG2 cells were transfected with either control vector, $\mathrm{Mcl}-1$ or Bcl- $\mathrm{x}_{\mathrm{L}}$ expression vectors (kindly provided by $\mathrm{C}$ Borner and $U$ Maurer, University of Freiburg, Germany), or the combination thereof, using the Amaxa nucleofection method.

Statistical analysis. Differences between data sets were analyzed by unpaired Students $t$-test. $P$-values $<0.05$ were considered statistically significant.

\section{Conflict of interest}

The authors declare no conflict of interest.

Acknowledgements. The authors would like to thank J-F Dufour for hepatocyte cell lines, $\mathrm{C}$ Borner and $U$ Maurer for $\mathrm{BCl}-\mathrm{x}_{\mathrm{L}}$ and $\mathrm{Mcl}-1$ expression plasmids, and the Brunner laboratory for technical support. This work was supported in part by grants from the Swiss National Science Foundation and the Swiss Cancer League to TB and NC, and the Ettore and Valleria Rossi Foundation to NC. DS was supported by an MD-PhD Fellowship from the Swiss National Science Foundation.

1. Gerl R, Vaux DL. Apoptosis in the development and treatment of cancer. Carcinogenesis 2005; 26: 263-270.

2. Schulze-Bergkamen $\mathrm{H}$, Krammer PH. Apoptosis in cancer-implications for therapy. Semin Oncol 2004; 31: 90-119.

3. Hanahan D, Weinberg RA. The hallmarks of cancer. Cell 2000; 100: 57-70.

4. Ashkenazi A, Pai RC, Fong S, Leung S, Lawrence DA, Marsters SA et al. Safety and antitumor activity of recombinant soluble Apo2 ligand. J Clin Invest 1999; 104: 155-162.

5. Walczak H, Miller RE, Ariail K, Gliniak B, Griffith TS, Kubin M et al. Tumoricidal activity of tumor necrosis factor-related apoptosis-inducing ligand in vivo. Nat Med 1999; 5: 157-163.

6. Frese S, Brunner T, Gugger M, Uduehi A, Schmid RA. Enhancement of Apo2L/TRAIL (tumor necrosis factor-related apoptosis-inducing ligand)-induced apoptosis in non-small cell lung cancer cell lines by chemotherapeutic agents without correlation to the expression level of cellular protease caspase-8 inhibitory protein. J Thorac Cardiovasc Surg 2002; 123: $168-174$.

7. Naka T, Sugamura K, Hylander BL, Widmer MB, Rustum YM, Repasky EA. Effects of tumor necrosis factor-related apoptosis-inducing ligand alone and in combination with chemotherapeutic agents on patients' colon tumors grown in SCID mice. Cancer Res 2002; 62: 5800-5806.

8. Ray S, Almasan A. Apoptosis induction in prostate cancer cells and xenografts by combined treatment with Apo2 ligand/tumor necrosis factor-related apoptosis-inducing ligand and CPT-11. Cancer Res 2003; 63: 4713-4723.

9. El-Deiry WS. Insights into cancer therapeutic design based on p53 and TRAIL receptor signaling. Cell Death Differ 2001; 8: 1066-1075.

10. Wu GS, Burns TF, McDonald III ER, Jiang W, Meng R, Krantz ID et al. KILLER/DR5 is a DNA damage-inducible p53-regulated death receptor gene. Nat Genet 1997; 17: 141-143.

11. Vivo C, Liu W, Broaddus VC. C-Jun N-terminal kinase contributes to apoptotic synergy induced by tumor necrosis factor-related apoptosis-inducing ligand plus DNA damage in chemoresistant, p53 inactive mesothelioma cells. J Biol Chem 2003; 278: 25461-25467.

12. Corazza N, Jakob S, Schaer C, Frese S, Keogh A, Stroka D et al. TRAIL receptor-mediated JNK activation and Bim phosphorylation critically regulate Fas-mediated liver damage and lethality. J Clin Invest 2006; 116: 2493-2499.

13. Kaufmann T, Jost PJ, Pellegrini M, Puthalakath $\mathrm{H}$, Gugasyan R, Gerondakis S et al. Fatal hepatitis mediated by tumor necrosis factor TNFalpha requires caspase- 8 and involves the BH3-only proteins Bid and Bim. Immunity 2009; 30: 56-66.

14. Wang S, El-Deiry WS. TRAIL and apoptosis induction by TNF-family death receptors Oncogene 2003; 22: 8628-8633.

15. Puthalakath $\mathrm{H}$, Huang DC, O'Reilly LA, King SM, Strasser A. The proapoptotic activity of the $\mathrm{Bcl}-2$ family member Bim is regulated by interaction with the dynein motor complex. Mol Cell 1999; 3: 287-296.

16. Lei K, Davis RJ. JNK phosphorylation of Bim-related members of the Bcl2 family induces Bax-dependent apoptosis. Proc Natl Acad Sci USA 2003; 100: 2432-2437.

17. Putcha GV, Le S, Frank S, Besirli CG, Clark K, Chu B et al. JNK-mediated BIM phosphorylation potentiates BAX-dependent apoptosis. Neuron 2003; 38: 899-914.

18. Puthalakath $H$, Strasser A. Keeping killers on a tight leash: transcriptional and posttranslational control of the pro-apoptotic activity of BH3-only proteins. Cell Death Differ 2002; 9: 505-512

19. Willis SN, Fletcher Jl, Kaufmann T, van Delft MF, Chen L, Czabotar PE et al. Apoptosis initiated when $\mathrm{BH} 3$ ligands engage multiple Bcl-2 homologs, not Bax or Bak. Science 2007; 315: 856-859.

20. Czabotar PE, Lee EF, van Delft MF, Day CL, Smith BJ, Huang DC et al. Structural insights into the degradation of Mcl-1 induced by BH3 domains. Proc Natl Acad Sci USA 2007; 104: 6217-6222.

21. Kaufmann T, Tai L, Ekert PG, Huang DC, Norris F, Lindemann RK et al. The BH3-only protein bid is dispensable for DNA damage- and replicative stress-induced apoptosis or cell-cycle arrest. Cell 2007; 129: 423-433

22. Yin X, Wang K, Gross A, Zhao Y, Zinkel S, Klocke B et al. Bid-deficient mice are resistant to Fas-induced hepatocellular apoptosis. Nature 1999; 400: 886-891.

23. Martin SJ, Green DR. Apoptosis as a goal of cancer therapy. Curr Opin Oncol 1994; 6 : 616-621.

24. Terradillos $\mathrm{O}$, Pollicino $\mathrm{T}$, Lecoeur $\mathrm{H}$, Tripodi $\mathrm{M}$, Gougeon $\mathrm{ML}$, Tiollais $\mathrm{P}$ et al. p53-independent apoptotic effects of the hepatitis $\mathrm{B}$ virus $\mathrm{HBx}$ protein in vivo and in vitro. Oncogene 1998; 17: 2115-2123.

25. Weiland T, Weiller M, Kunstle G, Wendel A. Sensitization by 5-azacytidine toward death receptor-induced hepatic apoptosis. J Pharmacol Exp Ther 2009; 328: 107-115.

26. Koschny R, Holland H, Sykora J, Erdal H, Krupp W, Bauer M et al. Bortezomib sensitizes primary human esthesioneuroblastoma cells to TRAIL-induced apoptosis. $J$ Neurooncol 2010; 97: 171-185

27. Jo M, Kim TH, Seol DW, Esplen JE, Dorko K, Billiar TR et al. Apoptosis induced in normal human hepatocytes by tumor necrosis factor-related apoptosis-inducing ligand. Nat Med 2000; 6: 564-567.

28. Owen-Schaub LB, Zhang W, Cusack JC, Angelo LS, Santee SM, Fujiwara T et al. Wild-type human $\mathrm{p} 53$ and a temperature-sensitive mutant induce Fas/APO-1 expression. Mol Cell Biol 1995; 15: 3032-3040.

29. Takimoto R, El-Deiry WS. Wild-type p53 transactivates the KILLER/DR5 gene through an intronic sequence-specific DNA-binding site. Oncogene 2000; 19: 1735-1743.

30. Ganten TM, Koschny R, Sykora J, Schulze-Bergkamen H, Buchler P, Haas TL et al. Preclinical differentiation between apparently safe and potentially hepatotoxic applications of TRAIL either alone or in combination with chemotherapeutic drugs. Clin Cancer Res 2006; 12: 2640-2646.

31. Lacour S, Hammann A, Grazide S, Lagadic-Gossmann D, Athias A, Sergent 0 et al. Cisplatin-induced CD95 redistribution into membrane lipid rafts of HT29 human colon cancer cells. Cancer Res 2004; 64: 3593-3598.

32. Erlacher M, Michalak EM, Kelly PN, Labi V, Niederegger H, Coultas L et al. BH3-only proteins Puma and Bim are rate-limiting for gamma-radiation- and glucocorticoid-induced apoptosis of lymphoid cells in vivo. Blood 2005; 106: 4131-4138. Epub 2005 Aug 4123.

33. Gilley J, Coffer PJ, Ham J. FOXO transcription factors directly activate bim gene expression and promote apoptosis in sympathetic neurons. J Cell Biol 2003; 162: 613-622.

34. Stahl M, Dijkers PF, Kops GJ, Lens SM, Coffer PJ, Burgering BM et al. The forkhead transcription factor FoxO regulates transcription of p27Kip1 and Bim in response to IL-2. $\mathrm{J}$ Immunol 2002; 168: 5024-5031.

35. Whitfield J, Neame SJ, Paquet L, Bernard O, Ham J. Dominant-negative c-Jun promotes neuronal survival by reducing BIM expression and inhibiting mitochondrial cytochrome $\mathrm{C}$ release. Neuron 2001; 29: 629-643. 
36. Bianchini R, Nocentini G, Krausz LT, Fettucciari K, Coaccioli S, Ronchetti S et al. Modulation of pro- and antiapoptotic molecules in double-positive (CD4+CD8+) thymocytes following dexamethasone treatment. J Pharmacol Exp Ther 2006; 319: 887-897.

37. Bouillet P, Purton JF, Godfrey DI, Zhang LC, Coultas L, Puthalakath H et al. BH3-only Bcl-2 family member Bim is required for apoptosis of autoreactive thymocytes. Nature 2002; 415 922-926.

38. Hubner A, Barrett T, Flavell RA, Davis RJ. Multisite phosphorylation regulates Bim stability and apoptotic activity. Mol Cell 2008; 30: 415-425.

39. Michalak EM, Villunger A, Adams JM, Strasser A. In several cell types tumour suppressor p53 induces apoptosis largely via Puma but Noxa can contribute. Cell Death Differ 2008; 15: 1019-1029.

40. Kuroda J, Puthalakath H, Cragg MS, Kelly PN, Bouillet P, Huang DC et al. Bim and Bad mediate imatinib-induced killing of $B c r / A b l+$ leukemic cells, and resistance due to their loss is overcome by a BH3 mimetic. Proc Natl Acad Sci USA 2006; 103: 14907-14912.

41. Nakabayashi H, Taketa K, Miyano K, Yamane T, Sato J. Growth of human hepatoma cells lines with differentiated functions in chemically defined medium. Cancer Res 1982; 42: 3858-3863.

42. Nguyen TH, Mai G, Villiger P, Oberholzer J, Salmon P, Morel P et al. Treatment of acetaminophen-induced acute liver failure in the mouse with conditionally immortalized human hepatocytes. J Hepatol 2005; 43: 1031-1037.
43. Strain AJ, Ismail $\mathrm{T}$, Tsubouchi $\mathrm{H}$, Arakaki $\mathrm{N}$, Hishida $\mathrm{T}$, Kitamura $\mathrm{N}$ et al. Native and recombinant human hepatocyte growth factors are highly potent promoters of DNA synthesis in both human and rat hepatocytes. J Clin Invest 1991; 87: 1853-1857.

44. Martin SJ, Reutelingsperger CP, McGahon AJ, Rader JA, van Schie RC, LaFace DM et al. Early redistribution of plasma membrane phosphatidylserine is a general feature of apoptosis regardless of the initiating stimulus: inhibition by overexpression of $\mathrm{Bcl}-2$ and $\mathrm{Abl}$. J Exp Med 1995; 182: 1545-1556.

45. Adrain C, Creagh EM, Martin SJ. Apoptosis-associated release of Smac/DIABLO from mitochondria requires active caspases and is blocked by Bcl-2. EMBO J 2001; 20: 6627-6636. published by Nature Publishing Group. This work is licensed under the Creative Commons Attribution-Noncommercial-No Derivative Works 3.0 Unported License. To view a copy of this license, visit http://creativecommons.org/licenses/by-nc-nd/3.0/ 